[Article]

\title{
ZnO/PPy 异质纳米复合材料的制备、表征及其气敏特性
}

\author{
杜海英 ${ }^{1,2}$ 王 兢 ${ }^{1, *}$ 乔 俏 ${ }^{1}$ 孙炎辉 ${ }^{1,2}$ 邵 强 ${ }^{2}$ 李晓干 ${ }^{1}$ \\ ('大连理工大学电子科学与技术学院, 辽宁大连 116023 ; ${ }^{2}$ 大连民族学院机电信息工程学院, 辽宁大连 116600)
}

摘要: 室温下, 采用原位聚合法, 以吡咯 (PY)为单体, 氯化铁 $\left(\mathrm{FeCl}_{3} \cdot 6 \mathrm{H}_{2} \mathrm{O}\right)$ 为氧化剂, 在塑料基片上聚合生长 了聚吡咯(PPy)纳米微球. 然后在聚吡咯基片上生长 $\mathrm{ZnO}$ 种子, 将表面种有 $\mathrm{ZnO}$ 种子的 PPy 元件置于六次甲基 四胺与硝酸锌的混合溶液中, $90^{\circ} \mathrm{C}$ 水浴中, 在 $\mathrm{PPy}$ 微球上生长了 $\mathrm{ZnO}$ 纳米棒, 合成了 $\mathrm{PPy} / \mathrm{ZnO}$ 异质纳米复合 材料. 分别通过 X射线衍射仪 (XRD) 和场发射扫描电镜(FESEM)对 PPy/ZnO 异质纳米复合材料的结构和形貌 进行了表征. 制备了塑料基的 PPy/ZnO 异质纳米复合材料气体传感器, 在室温下, 对 $10 \times 10^{-6}-150 \times 10^{-6}$ (体积 分数)浓度范围的氨气进行了气敏测试, PPy/ZnO气敏元件对氨气响应的灵敏度基本呈线性关系, 且对甲醇、丙 酮、甲苯等有机气体表现出很好的选择性. 最后, 对 PPy/ZnO 异质纳米复合材料的形成机理进行了简要分析.

关键词: 原位聚合法; 异质纳米复合物; 气体传感器; 气敏特性; 形成机理 中图分类号: 0649

\section{Synthesis and Characterization of ZnO/PPy Hetero-Nanocomposites and Their Gas Sensing Properties}

\author{
DU Hai-Ying ${ }^{1,2} \quad$ WANG Jing,"* $\quad$ QIAO Qiao ${ }^{1} \quad$ SUN Yan-Hui ${ }^{1,2}$ \\ SHAO Qiang ${ }^{2} \quad$ LI Xiao-Gan ${ }^{1}$
}

('School of Electronic Science and Technology, Dalian University of Technology, Dalian 116023, Liaoning Province, P. R. China; ${ }^{2}$ College of Electromechanical \& Information Engineering, Dalian Nationalities University,

Dalian 116600, Liaoning Province, P. R. China)

\begin{abstract}
Pyrrole (Py) was oxidized by ferric(III) chloride solution in water for the synthesis of polypyrrole (PPy) nanoparticles on the substrate slide by in-situ polymerization at room temperature. Zinc oxide nanorods grew on the PPy nanoparticles when in a water bath at $90^{\circ} \mathrm{C}$. ZnO/PPy hetero-nanocomposites were obtained by a hydrothermal method and characterized using X-ray diffraction (XRD) and field emission scanning electron microscopy (FESEM). Gas sensors were fabricated based on the ZnO/PPy hetero-nanocomposites to detect ammonia at room temperature. The gas sensing properties of these hetero-nanocomposites were measured in the concentration range of $10 \times 10^{-6}-150 \times 10^{-6}$ (volume fraction). The relationship of the sensitivity of the sensors to the ammonia concentration showed linearity. The gas sensor based on ZnO/PPy heteronanocomposites showed good selectivity to ammonia when in the presence of interfering gases such as methanol, acetone, and toluene. The formation mechanism of the ZnO/PPy hetero-nanocomposites was briefly analyzed.
\end{abstract}

Key Words: In-situ polymerization; Hetero-nanocomposite; Gas sensor; Gas sensing property; Formation mechanism

Received: December 12, 2014; Revised: Janaury 27, 2015; Published on Web: January 28, 2015.

"Corresponding author. Email: wangjing@dlut.edu.cn; Tel: +86-411-84708382; Fax: +86-411-84706706.

The project was supported by the National Natural Science Foundation of China $(61176068,61131004,61474012)$.

国家自然科学基金(61176068, 61131004, 61474012)资助项目

(c) Editorial office of Acta Physico-Chimica Sinica 


\section{Introduction}

The discovery of conductive polymers since the 70s last century ${ }^{1}$ has initiated intense experimental and theoretical interest in various fields of industrial and agricultural production and became an irreplaceable foundation of polymer material for its special structure and excellent physical and chemical properties. Common conductive polymers include polyacetylene $(\mathrm{PA}),{ }^{2}$ polyaniline (PANI), ${ }^{3}$ polythiophene (PT), ${ }^{4}$ polypyrrole (PPy). ${ }^{5}$

Among various conducting polymers, PPy is an outstanding member with particular importance in sensing applications for its chemical stability and ease of synthesis. ${ }^{6,7}$ The use of PPy-based electronic noses (ENs) for environmental and industrial analysis has gained considerable momentum. Toxic and non-toxic substances, such as ammonia, nitrogen oxides, carbon monoxide, sulphur dioxide, hydrogen sulphide, methane, oxygen, hydrogen, alcohols, phenol, benzene, and water vapours, have been successfully determined by PPy-based ENs in materials ranging from water and beverages to waste waters and sewage effluents. ${ }^{8}$

Polypyrrole has shown great potentials for application in various fields of industrial and agricultural production, such as biosensors, ${ }^{9}$ gas sensors, ${ }^{10}$ electrochemical sensors, ${ }^{11,12}$ anti-corrosion coating materials, ${ }^{13}$ electrode materials, ${ }^{14}$ antistatic materials,${ }^{15}$ and so on. ${ }^{16}$ As a $p$ type organic semiconductor, polypyrrole alters its chemical behavior and consequently its electrical conductivity which makes it excellent gas sensing material. ${ }^{17,18}$

Metal oxide semiconductors, such as $\mathrm{SnO}_{2},{ }^{19} \mathrm{In}_{2} \mathrm{O}_{3}{ }^{20} \mathrm{TiO}_{2},{ }^{21}$ $\mathrm{ZnO}^{22}$ and $\mathrm{ZrO},{ }^{23}$ are the popular materials for gas sensors. Zinc oxide $(\mathrm{ZnO})$ is an important II-VI semiconducting material with a wide band gap of $3.37 \mathrm{eV}$ and a large exciton binding energy of $60 \mathrm{meV}$. $\mathrm{ZnO}$ is recognized as one of the key functional metaloxide semiconductors owing to its outstanding optical, gas, electrical, piezoelectrical properties, and the diversity of nanostructures. Single crystal $\mathrm{ZnO}$ nanorod arrays have no grain boundaries, less crystal defects, big surface area, which has promising applications in fields of functional materials and catalysis. ${ }^{24,25}$

Inorganic nanoparticles and organic polymer nanocomposites show the excellent gas, humidity, and electrochemical performance. The sensors based on inorganic and organic nanocomposites show high response sensitivity, low operating temperature, and other advantageous properties. These nanocomposites with excellent properties have wide applications. ${ }^{26,27}$

In this report, $\mathrm{ZnO} / \mathrm{PPy}$ hetero-nanocomposites were synthesized by in-situ polymerization and hydrothermal synthesis twostep method and the gas sensor based on $\mathrm{ZnO} / \mathrm{PPy}$ hetero-nanocomposites was fabricated, the $\mathrm{ZnO} / \mathrm{PPy}$ sensor exhibits good sensitivity to ammonia at room temperature. Formation mechanism and adsorption mechanism of the $\mathrm{ZnO} / \mathrm{PPy}$ hetero-nanocomposites were briefly analyzed.

\section{Experimental}

\subsection{Preparation of the slide substrate}

In the typical experiment, the slide was cut into strip $(1 \mathrm{~cm} \times 1.5$ $\mathrm{cm}$ ), then washed with deionized water and acetone for several times, respectively. And the strip was dried by blowing with a stream of nitrogen. One pair of platinum electrodes were coated at both side of the slide, and two platinum bond wires were leaded on the slide surface electrodes. Fig.1 gives the sketch of gas sensor structure based on slide film.

\subsection{Synthesis of PPy}

Monomer pyrrole (Py) ( $\geqslant 99.5 \%$ purity), ferric(III) chloride $\left(\mathrm{FeCl}_{3} \cdot 6 \mathrm{H}_{2} \mathrm{O}\right)\left(\geqslant 99.5 \%\right.$ purity), acetone $\left(\mathrm{CH}_{3} \mathrm{COCH}_{3}\right)(\geqslant 99.7 \%$ purity), and ethanol (EtOH) ( $\geqslant 99.0 \%$ purity) were obtained from Sinopharm Chemical Reagent Co., Ltd., China. Zinc acetate $\left(\mathrm{Zn}\left(\mathrm{CH}_{3} \mathrm{COO}\right)_{2} \cdot 2 \mathrm{H}_{2} \mathrm{O}\right)(\geqslant 99.5 \%$ purity $)$ and zinc nitrate hexahydrate $\left(\mathrm{Zn}\left(\mathrm{NO}_{3}\right)_{2} \cdot 6 \mathrm{H}_{2} \mathrm{O}\right)(\geqslant 99.5 \%$ purity) were obtained from Tianjin Kermel Chemical Company, China. The above chemical reagents were analytical grade and used without further purification.

$230 \mathrm{mg}$ of pyrrole monomer ( $\geqslant 99.7 \%$ purity) was dissolved in $50 \mathrm{~mL}$ deionized water and treated with ultrasonic for $20 \mathrm{~min}$ for uniformly dispersing in deionized water. Then the slide substrates were immersed into the aqueous solution and suspended in the container. The chemical polymerization was carried out in a beaker by mixing $1350 \mathrm{mg}$ of $\mathrm{FeCl}_{3} \cdot 6 \mathrm{H}_{2} \mathrm{O}$ powder into the above suspension under vigorous stirring at room temperature for $3 \mathrm{~h}$. Thin films of PPy were in-situ deposited simply by keeping a precleaned slide substrate suspending in the suspension. After termination of polymerization, films were washed with deionized water and acetone for several times, respectively, and dried under vacuum for $24 \mathrm{~h}$. Polymerization product in the solution was collected by centrifugal filtration.

\subsection{ZnO nanorod growth process}

$219 \mathrm{mg}$ of zinc acetate $\left(\mathrm{Zn}\left(\mathrm{CH}_{3} \mathrm{COO}\right)_{2} \cdot 2 \mathrm{H}_{2} \mathrm{O}\right)$ was dissolved in $20 \mathrm{~mL}$ ethanol to form a solution with concentration of $0.05 \mathrm{~mol}$. $\mathrm{L}^{-1}$. Then the solution was ultrasonically agitated for $0.5 \mathrm{~h}$ to obtain a uniform and transparent zinc acetate solution. The zinc acetate solution was heated at $200{ }^{\circ} \mathrm{C}$ for $30 \mathrm{~min}$, then the solution was coated onto cleaned PPy gas sensor by a spin coater at the rate of $2200 \mathrm{r} \cdot \mathrm{min}^{-1}$ for $30 \mathrm{~s}$. In our experiment, substrates were spin coated for three times. The coated substrates were dried in room temperature and then annealed at $100{ }^{\circ} \mathrm{C}$ for $90 \mathrm{~min}$ in air to form the $\mathrm{ZnO}$ seed layer on the PPy thin films. Finally, the $\mathrm{ZnO}$ nanorods grew directly by placing the PPy thin films covered with a layer of $\mathrm{ZnO}$ seed in $50 \mathrm{~mL}$ aqueous solution of $57 \mathrm{mmol} \cdot \mathrm{L}^{-1}$ $\mathrm{Zn}\left(\mathrm{NO}_{3}\right)_{2} \cdot 6 \mathrm{H}_{2} \mathrm{O}$ and $57 \mathrm{mmol} \cdot \mathrm{L}^{-1}$ hexamethylenetetramine

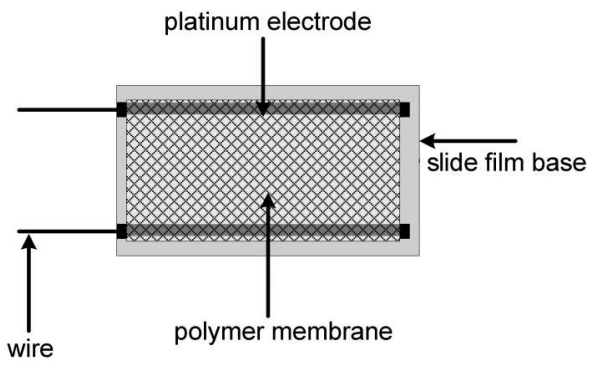

Fig.1 Sketch of gas sensor structure based on slide film 
$\left(\mathrm{C}_{6} \mathrm{H}_{12} \mathrm{~N}_{4}\right)$ at $90{ }^{\circ} \mathrm{C}$ for $12 \mathrm{~h}$. The substrates covered with the $\mathrm{ZnO}$ nanorods were washed with deionized water and acetone, followed by dring in a nitrogen stream. Gas sensor with $\mathrm{ZnO}$ nanorods grown on the PPy seed layer was obtained.

\subsection{Characterization}

The structures of the $\mathrm{ZnO} / \mathrm{PPy}$ hetero-nanocomposites were characterized by an X-ray diffraction instrument (XRD, D/Max 2400 , Rigaku, Japan) in a $2 \theta$ region of $20^{\circ}-80^{\circ}$ with $\mathrm{Cu} K_{a 1}$ radiation. The morphology images of $\mathrm{ZnO} / \mathrm{PPy}$ hetero-nanocomposites were obtained by using field emission scanning electron microscope (FESEM, Hitachi S-4800, Japan) and transmission electron microscope (TEM, Tecnai 20, USA).

\subsection{Testing of sensors}

The gas sensing properties of $\mathrm{ZnO} / \mathrm{PPy}$ hetero-nanocomposites sensor were measured using a static state gas sensing test system. Structure schematic diagram of the static state gas sensing test system is shown in Fig.2. In the gas response measurement, a given amount of target gas was injected into a test chamber $(50 \mathrm{~L}$ in volume) by a syringe through a rubber plug. For a required concentration, the volume of the injected gas $(V)$ can be calculated as follows:

$$
V=\frac{50 \times C}{v}
$$

where $C$ is the concentration of the target gas (volume fraction), and $v$ is the volume fraction of bottled gas. Sensors were exposed to the atmospheric air by opening the chamber after the measurement. The export voltage on the sensor was measured by using a voltage division circuit on which the voltage is $10 \mathrm{~V}$, and the sensor was connected in series with an external resistance $\left(R_{\mathrm{L}}\right)$. The gas response value $(S)$ was defined as a ratio of the resistance of the sensor in air $\left(R_{\mathrm{a}}\right)$ to that in target gas $\left(R_{\mathrm{g}}\right): S=R_{\mathrm{g}} / R_{\mathrm{a}}$, and $R_{\mathrm{a}}=$ $R_{\mathrm{L}}\left(10-V_{\text {air }}\right) / V_{\text {air }}, R_{\mathrm{g}}=R_{\mathrm{L}}\left(10-V_{\text {gas }}\right) / V_{\text {gas }}$, where $V_{\text {air }}$ is the export voltage of $R_{\mathrm{L}}$ in air, and $V_{\text {gas }}$ is the voltage in target gas. All the tests were operated at room temperature about $35 \%$ relative humidity $(\mathrm{RH})$.

\section{Results and discussion}

\subsection{Materials characterization}

Fig. 3 shows the XRD patterns of the $\mathrm{ZnO}, \mathrm{PPy}$, and $\mathrm{ZnO} / \mathrm{PPy}$ hetero-nanocomposites. We can see from Fig.3(a) that major peaks

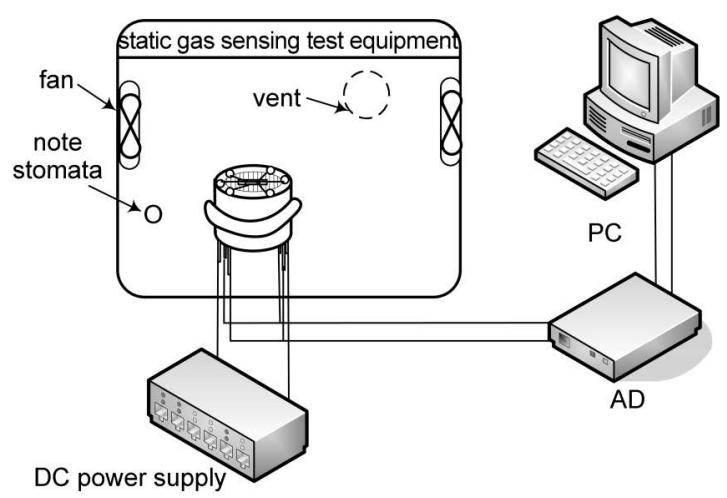

Fig.2 Structure schematic diagram of the static state gas sensing test system

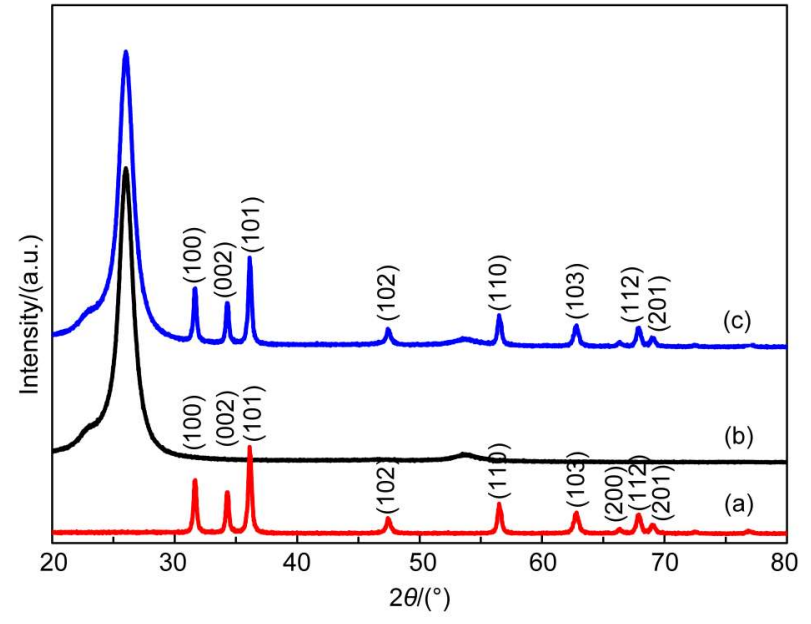

Fig.3 XRD patterns of (a) ZnO, (b) PPy, and

(c) $\mathrm{ZnO} / \mathrm{PPy}$ hetero-nanocomposites

of $\mathrm{ZnO}$ are shown at $31.8^{\circ}, 34.3^{\circ}, 36.1^{\circ}, 47.4^{\circ}$, and $62.8^{\circ}$, which are related to (100), (002), (101), (102), and (103) plane reflections of a hexagonal $\mathrm{ZnO}$, respectively, with lattice constants $a=$ $0.325 \mathrm{~nm}$ and $c=0.521 \mathrm{~nm}$ as denoted by International Center for Diffraction Data (Joint Committee for Powder Diffraction Studies (JCPDS) card \#36-1451) for ZnO. From Fig.3(b) we can see that the characteristic peak of PPy is observed at $2 \theta=25.0^{\circ}$. The average crystalline size of the PPy nanoparticles is calculated about $78.3 \mathrm{~nm}$ by Debye Scherror formula. From Fig.3(c) we can see that the characteristic peaks of PPy and hexagonal $\mathrm{ZnO}$ exist simultaneously in $\mathrm{ZnO} / \mathrm{PPy}$ hetero-nanocomposites.

Fig. 4 gives the SEM image of PPy nanoparticles. We can see that there is a layer of PPy nanoparticle (uniform thickness of about $200 \mathrm{~nm}$ ) aggregation grown in the slide substrate. The grain size of the PPy nanoparticles is $\sim 100 \mathrm{~nm}$.

Fig.5(a, b) give the SEM images of the $\mathrm{ZnO}$ nanorods grown on as-prepared PPy nanoparticle substrate after $9 \mathrm{~h}$ in different magnifications. Fig.5(c, d) give the SEM images of the $\mathrm{ZnO}$ nanorods grown on as-prepared substrate after $12 \mathrm{~h}$. From Fig.5(a, b) we can see that the surface of the thin films of PPy has been coated with uniform-sized $\mathrm{ZnO}$ nanorods after $9 \mathrm{~h}$. The length of $\mathrm{ZnO}$ nanorods is irregular and about $0-2.5 \mu \mathrm{m}$, the diameter of $\mathrm{ZnO}$ nanorods is about $10-200 \mathrm{~nm}$. As the time increasing, a large quantity of $\mathrm{ZnO}$ nanorods with uniform-sized are formed on the surface of PPy nanoparticles substrate after 12 h (Fig.5(c, d)). We

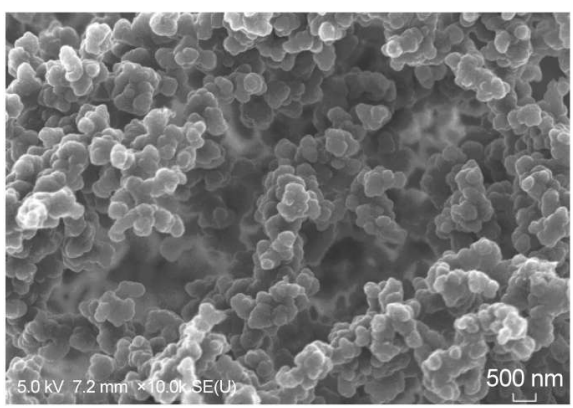

Fig.4 SEM image of PPy 


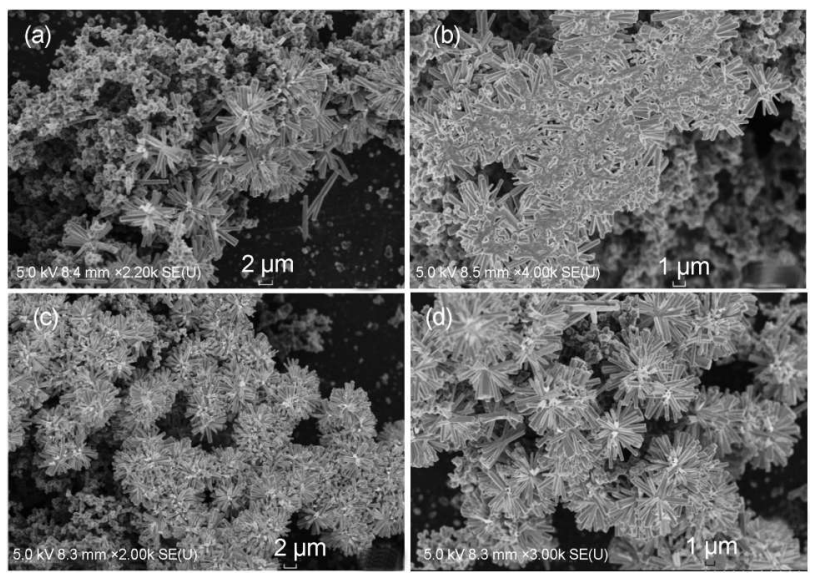

Fig.5 SEM images of $\mathrm{ZnO}$ grown on the PPy after $9 \mathrm{~h}(\mathrm{a}, \mathrm{b})$ and 12 h (c, d)

can see that the length and diameter of $\mathrm{ZnO}$ nanorods are about $2.5 \mu \mathrm{m}$ and $200 \mathrm{~nm}$, respectively. Many $\mathrm{ZnO}$ nanorods grown on the PPy nanoparticles, form flower- like $\mathrm{ZnO}$ nanorods. The magnified SEM image of flower-like $\mathrm{ZnO}$ nanorods grown on the PPy nanoparticles substrate is shown in Fig.6.

\subsection{Formation mechanism of $\mathrm{ZnO} / \mathrm{PPy}$ hetero- nanocomposites}

Pyrrole monomer is five-membered heterocyclic molecules containing carbon $(\mathrm{C})$ and nitrogen $(\mathrm{N})$ elements. The polymerization of the pyrrole monomer could occur under the electric field or the effect of the oxidant. The polymerization reaction equation is shown in Eq.(2).

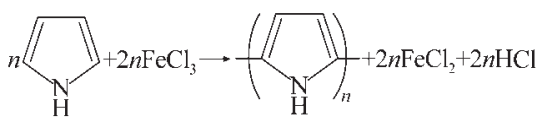

The formation mechanism of the flower-like $\mathrm{ZnO}$ nanorods by using the hydrothermal method could be described as follows: HMTA $\left(\mathrm{C}_{6} \mathrm{H}_{12} \mathrm{~N}_{4}\right)$ was extensively used in the fabrication of nanostructure $\mathrm{ZnO}$, and it provided ammonia molecules and the hydroxide ions $\left(\mathrm{OH}^{-}\right)$to the solution (Eqs.(3) and (4)). $\mathrm{Zn}\left(\mathrm{NO}_{3}\right)_{2} \cdot 6 \mathrm{H}_{2} \mathrm{O}$ was used to provide the zinc ions (Eq.(5)), apparently. In this experiment, the numbers of $\mathrm{OH}^{-}$were abundant in the mixed solution of $\mathrm{Zn}\left(\mathrm{NO}_{3}\right)_{2} \cdot 6 \mathrm{H}_{2} \mathrm{O}$ and HMTA $\left(\mathrm{C}_{6} \mathrm{H}_{12} \mathrm{~N}_{4}\right)$. So, $\mathrm{Zn}(\mathrm{OH})_{2}$ precipitation formed as Eq.(6), and then $\mathrm{Zn}(\mathrm{OH})_{2}$ could be dissolved immediately by reacting with superfluous $\mathrm{OH}^{-}$ions, the

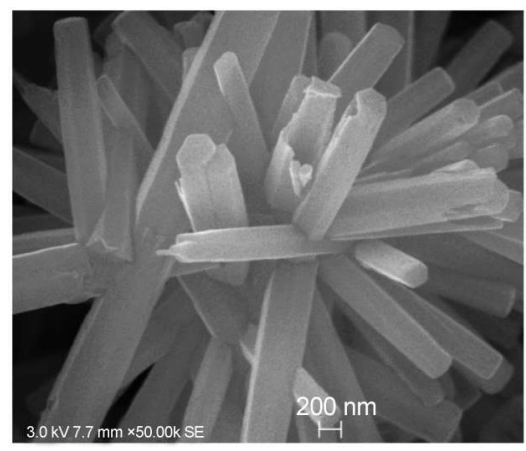

Fig.6 SEM image of ZnO nanorods grown on PPy transparent $\mathrm{Zn}(\mathrm{OH})_{4}^{2-}$ solution was obtained as Eq.(7). In the hydrothermal process, the $\mathrm{Zn}(\mathrm{OH})_{4}^{2-}$ grew units combined with each other and dehydrated into $\mathrm{ZnO}$ nuclei simultaneously. And then these $\mathrm{ZnO}$ nuclei self-assembled to form the rod-like nanostructures along a preferred axis orientation (Eq.(8)).

$$
\begin{aligned}
& \mathrm{C}_{6} \mathrm{H}_{12} \mathrm{~N}_{4}+6 \mathrm{H}_{2} \mathrm{O} \rightleftharpoons 6 \mathrm{HCHO}+4 \mathrm{NH}_{3} \\
& \mathrm{NH}_{3}+\mathrm{H}_{2} \mathrm{O} \rightleftharpoons \mathrm{NH}_{4}^{+}+\mathrm{OH}^{-} \\
& \mathrm{Zn}\left(\mathrm{NO}_{3}\right)_{2} \rightarrow \mathrm{Zn}^{2+}+2 \mathrm{NO}_{3}^{-} \\
& \mathrm{Zn}^{2+}+2 \mathrm{OH}^{-} \rightarrow \mathrm{Zn}(\mathrm{OH})_{2} \\
& \mathrm{Zn}(\mathrm{OH})_{2}+2 \mathrm{OH}^{-} \rightarrow \mathrm{Zn}(\mathrm{OH})_{4}^{2-} \\
& \mathrm{Zn}(\mathrm{OH})_{4}^{2-} \rightarrow \mathrm{ZnO}+\mathrm{H}_{2} \mathrm{O}+2 \mathrm{OH}^{-}
\end{aligned}
$$

\subsection{Gas sensing properties}

At room temperature, the ammonia gas sensing properties of $\mathrm{ZnO} / \mathrm{PPy}$ hetero-nanocomposite gas sensor were measured. Fig.7 shows the response and recovery transient properties of the $\mathrm{ZnO} /$ PPy hetero-nanocomposite gas sensor to ammonia at room temperature. The concentration range of ammonia is $10 \times 10^{-6}-$ $150 \times 10^{-6}$, and the relative humidity $(\mathrm{RH})$ was $35 \%$. We can see from the figure that the eight response cycles are recorded successively, and the gas sensor based on $\mathrm{ZnO} / \mathrm{PPy}$ hetero-nanocomposites shows good sensitivities to ammonia. The response of $\mathrm{ZnO} / \mathrm{PPy}$ hetero-nanocomposite sensor to $150 \times 10^{-6}$ ammonia is 2.51. The lowest concentration of ammonia detected by the sensor of $\mathrm{ZnO} / \mathrm{PPy}$ hetero-nanocomposites is $10 \times 10^{-6}$ with a response of 1.36. The response and recovery times of the sensors are about 200 and $1000 \mathrm{~s}$, respectively, as shown in the enlarged curve (the inset curve in Fig.7), which are defined as the times reaching 90\% of the final values.

The response values of the sensors based on $\mathrm{ZnO} / \mathrm{PPy}$ heteronanocomposites at room temperature $v s$ ammonia concentration are illustrated in Fig.8. For comparison, the ammonia gas sensing properties of $\mathrm{ZnO}$ and PPy gas sensors were measured in concentration range of $10 \times 10^{-6}-150 \times 10^{-6}$ at room temperature. We can see that the response curves of $\mathrm{ZnO}, \mathrm{PPy}$, and $\mathrm{ZnO} / \mathrm{PPy}$ sensors are nearly linearity in concentration range of $10 \times 10^{-6}-$ $150 \times 10^{-6}$ at room temperature. However the response of $\mathrm{ZnO}$ sensor is the lowest in the three sensors at the room temperature.

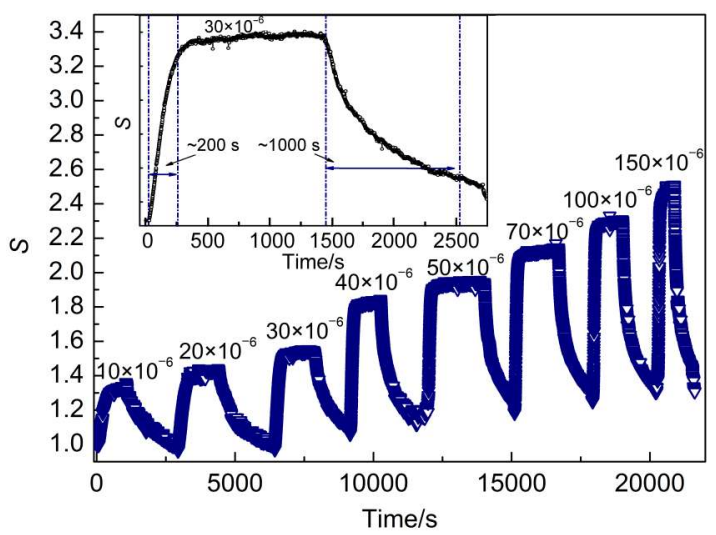

Fig.7 Transient response curves of gas sensor based on $\mathrm{ZnO/PPy}$ hetero-nanocomposites to ammonia $S=R_{\mathrm{g}} / R_{\mathrm{a}}$ 


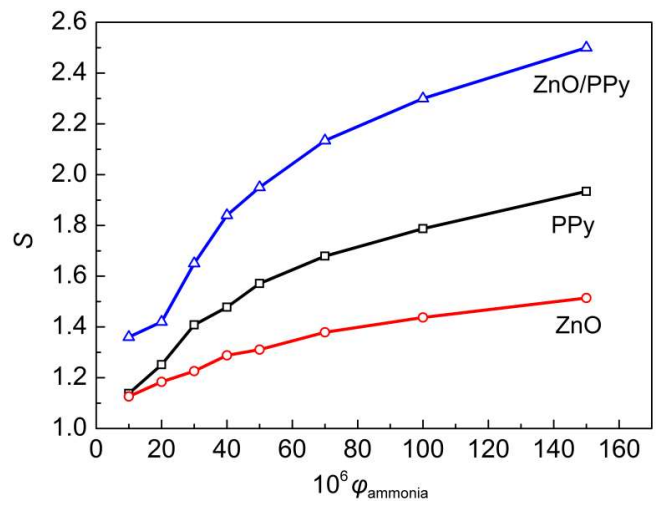

Fig.8 Response values of the gas sensor based on $\mathrm{ZnO} / \mathrm{PPy}$ hetero-nanocomposites vs ammonia concentration

The response of $\mathrm{ZnO} / \mathrm{PPy}$ sensor is much higher than that of $\mathrm{ZnO}$ or PPy sensor. The response curves of $\mathrm{ZnO} / \mathrm{PPy}$ sensors show good linearity in ammonia gas concentration range of $20 \times 10^{-6}-$ $80 \times 10^{-6}$ at room temperature.

The cross-response curves of $\mathrm{ZnO} / \mathrm{PPy}$ hetero-nanocomposite sensor to ammonia, formaldehyde, ethanol, and toluene at room temperature in the concentration range of $10 \times 10^{-6}-150 \times 10^{-6}$ are demonstrated in Fig.9, respectively. The selectivity property of the sensor indicates that $\mathrm{ZnO} / \mathrm{PPy}$ hetero-nanocomposite sensors get higher response to ammonia than to ethanol, and hardly sensitive to toluene and formaldehyde.

To investigate the long time stability of $\mathrm{ZnO} / \mathrm{PPy}$ heteronanocomposite sensor, the responses of $\mathrm{ZnO} / \mathrm{PPy}$ sensor to $10 \times 10^{-6}$, $50 \times 10^{-6}$ and $100 \times 10^{-6}$ ammonia were repeated after 1 day, 1 month, and 3 months. Fig. 10 gives the responses of $\mathrm{ZnO} / \mathrm{PPy}$ hetero-nanocomposite, sensor to ammonia with different concentrations after 1 day, 1 month, and 3 months at room temperature, respectively. It can be seen from the figure that $\mathrm{ZnO} / \mathrm{PPy}$ sensor exhibited a nearly stable signal during the test, indicating a good stability of $\mathrm{ZnO} / \mathrm{PPy}$ sensor.

\subsection{Gas sensing mechanism}

The experiments show that $\mathrm{ZnO} / \mathrm{PPy}$ hetero-nanocomposite sensor is sensitive to ammonia at room temperature, which means that adsorption capability of $\mathrm{ZnO} / \mathrm{PPy}$ hetero-nanocomposites to ammonia at room temperature is improved. The reasons are an-

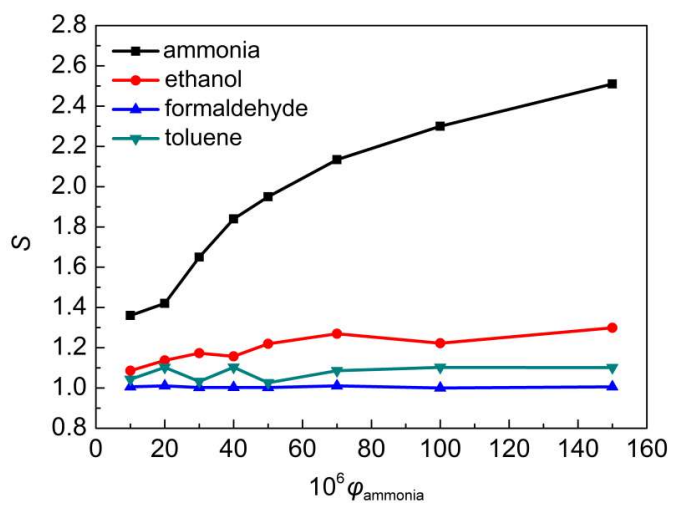

Fig.9 Cross-response curves of $\mathrm{ZnO} / \mathrm{PPy}$ hetero-nanocomposite sensor to ammonia, formaldehyde, ethanol, and toluene

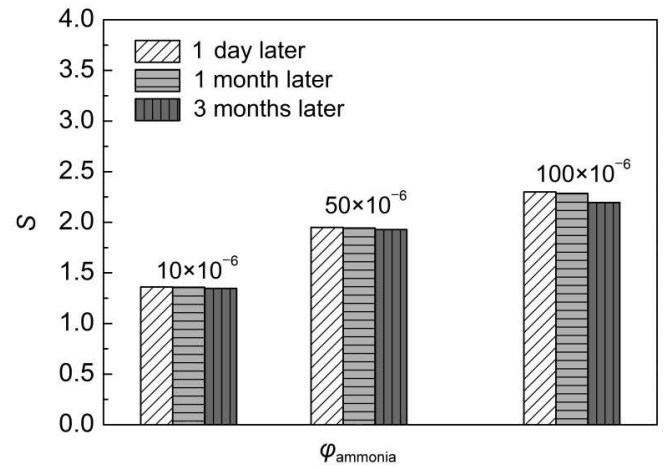

Fig.10 Stability of $\mathrm{ZnO} / \mathrm{PPy}$ sensor to different concentrations of ammonia after 1 day, 1 month, and 3 months at room temperature

alyzed as follows.

The stable oxygen ions were $\mathrm{O}_{2}^{-}$below $100{ }^{\circ} \mathrm{C}, \mathrm{O}^{-}$between 100 and $300{ }^{\circ} \mathrm{C}$, and $\mathrm{O}^{2-}$ above $300{ }^{\circ} \mathrm{C}^{28}$ When the PPy is exposed to air at room temperature, oxygen molecules adsorb on the surface of PPy nanoparticles to form $\mathrm{O}_{2}^{-}$species by capturing electrons from the conductance band. ${ }^{28}$

It is well known that PPy is a $p$ type semiconductor. Holes are the majority carrier, and recombination is limited by electron injection. When PPy nanoparticle is exposed to reductive gas ammonia at room temperature, the ammonia molecules will react with the surface $\mathrm{O}_{2}^{-}$species and release electrons, which will combine with the holes to result in the decreasing of carrier concentration. The resistance of PPy nanoparticles will increase. ${ }^{29,30}$ But as for a typical $n$ type sensor, electrons are the majority carrier. When $\mathrm{ZnO}$ is exposed to reductive gas ammonia at room temperature, the carrier concentration of the $\mathrm{ZnO}$ will increase and the resistance will decrease, correspondingly. They have opposite electrical behavior when the $\mathrm{ZnO} / \mathrm{PPy}$ hetero-nanocomposite gas sensor is exposed to the reductive gas ammonia at room temperature. Two kinds of barriers ( $\mathrm{ZnO}$ and PPy) exist in the treated $\mathrm{ZnO} / \mathrm{PPy}$ hetero-nanocomposites, the barriers between homogeneous nanocrystallites of $\mathrm{ZnO}$ and/or PPy, respectively. The barrier between $\mathrm{ZnO}$ and PPy is a $p$ - $n$ type hetero-junction in $\mathrm{ZnO} / \mathrm{PPy}$ composite material. Electron transport is expected to be strongly tuned by the hetero-junction barrier, which has been widely investigated for many hetero-junction devices such as lasers, photodiodes, and hetero-junction bipolar transistors. ${ }^{31,32}$ The energy band structure of the $\mathrm{ZnO} / \mathrm{PPy}$ hetero-junction can be schematically depicted in Fig. 11, where $\varphi^{\text {eff }}$ denotes the effective barrier height, considering the contribution of other factors such as temperature to the barrier height. ${ }^{33,34}$ Therefore, it requires that the transport of electrons should overcome the hetero-junction barriers. ${ }^{33,34}$ At the high temperature region, the electron motility $(\mu)$ is expressed by ${ }^{33}$

$$
\mu=\mu_{0} \exp \left(-q \varphi^{\mathrm{eff}} / k_{\mathrm{B}} T\right)
$$

where $\mu_{0}$ is a constant, $q$ is the charge of an electron, $k_{\mathrm{B}}$ is Boltzmann's constant, and $T$ is absolute temperature. According to Eq.(9), the conductivity $(G)$ of heterostructures under different gas atmospheres can be given by ${ }^{33}$ 


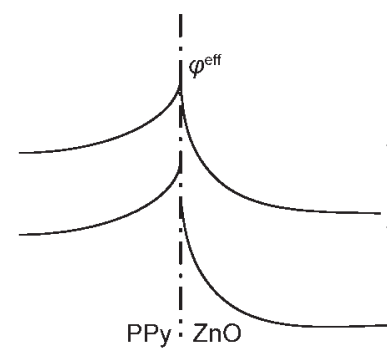

(a) in air

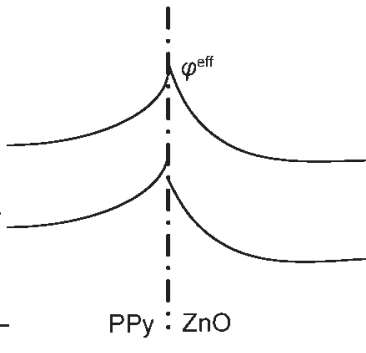

(b) in ammonia
Fig.11 A schematic diagram of the energy band structure of the $\mathrm{ZnO} / \mathrm{PPy}$ hetero-nanostructures

$$
G=G_{0} \exp \left(-\varphi^{\text {eff }} / k_{\mathrm{B}} T\right)
$$

In this equation, $G_{0}$ can be considered as a constant parameter. The conductivity of the hetero-junction is very high for $\mathrm{ZnO} / \mathrm{PPy}$. When the $\mathrm{ZnO} / \mathrm{PPy}$ hetero-structures are exposed to ammonia, the reaction between the adsorbed oxygen species and the ammonia molecules leads to the release of the trapped electrons back simultaneously into the conduction bands of the PPy and $\mathrm{ZnO}$, resulting in an increase in the width and height of the barrier potential at their interfaces, as shown in Fig.11(b). According the Eq.(10), the conductivity of the hetero-junction will consequently be greatly decreased, resulting in high sensitivity of the $\mathrm{ZnO} / \mathrm{PPy}$ composite materials to ammonia. ${ }^{34}$

The band model of $p-n$ type semiconductor in balance state is shown in Fig.12. At the same time, in $p$ - $n$ type semiconductor, the number of holes is larger than that of electrons in $p$ type region and the number of electrons is larger than that of holes in $n$ type region, which will cause the movement of the carriers. With the

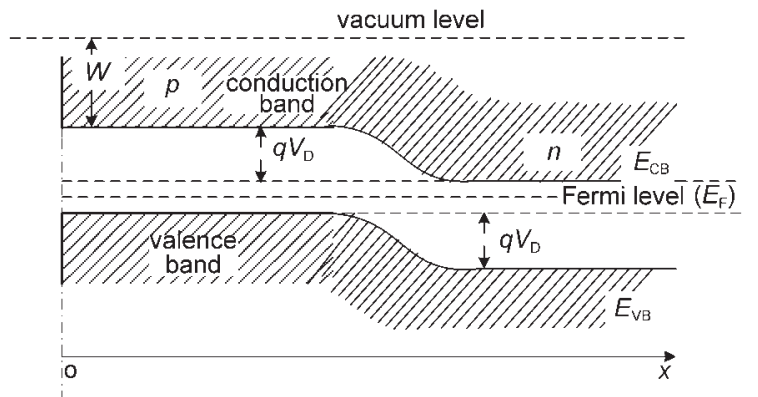

Fig.12 Band model of $\boldsymbol{p}$ - $\boldsymbol{n}$ type semiconductor in balance state $W$ : the electron affinity, $E_{\mathrm{CB}}$ : the donor level, $E_{\mathrm{VB}}$ : the acceptor level, $V_{\mathrm{D}}$ : the built-in electric potential barrier

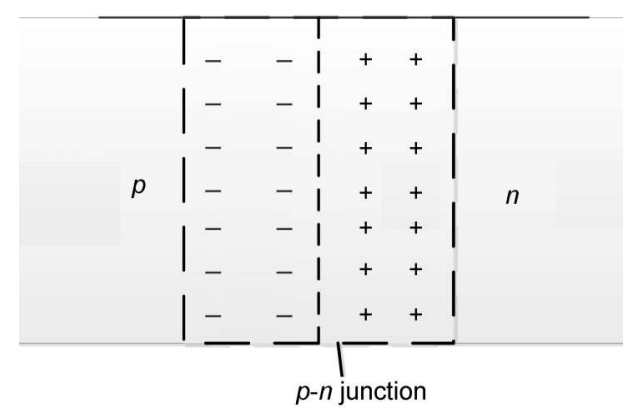

Fig.13 Space charge region schematic of $p$ - $n$ type semiconductor movement of the carriers, a space charge region will form between the $p$ type region and $n$ type region. When meeting the target gas, carriers will speed up in the space charge region, so the resistance of gas sensor decreases and the response of the sensor increases. ${ }^{35}$ The space charge region schematic of $p$ - $n$ type semiconductor is shown in Fig.13.

\section{Conclusions}

In summary, $\mathrm{ZnO} / \mathrm{PPy}$ hetero-nanocomposites are synthesized on the surface of the pre-treated slide substrate by in-situ polymerization and hydrothermal method. And then a large quantity of $\mathrm{ZnO}$ nanorods with uniform-size is formed in the surface of PPy by hydrothermal method. The ZnO/PPy nanocomposites are synthesized by the two-step method. The structure and morphology of the films are confirmed by XRD and SEM techniques, respectively. These films get good selectivity to ammonia, formaldehyde, methanol, and acetone. And the response increases as the ammonia concentration increases at room temperature. For ammonia vapor at concentration levels of $100 \times 10^{-6}$ and $150 \times 10^{-6}$, the responses are about 1.36 and 2.51, respectively. These studies suggest that $\mathrm{ZnO} / \mathrm{PPy}$ nanocomposites can be used for fabrication of ammonia sensors operated at room temperature. Our results demonstrate that $\mathrm{ZnO} / \mathrm{PPy}$ nanocomposites are very promising for fabricating sensors as well as other complex devices.

\section{References}

(1) Ito, T.; Shirakawa, H.; Ikeda, S. J. Polym. Sci. Part A: Polym. Chem. 1996, 34, 2533.

(2) Shirakawa, H.; Ikeda, S.; Aizawa, M.; Yoshitake, J.; Suzuki, S. Synth. Met. 1981, 4, 43. doi: 10.1016/0379-6779(81)90056-4

(3) Ayad, M. M.; Salahuddin, N. A.; Alghaysh, M. O.; Issa, R. M. Curr. Appl. Phys. 2010, 10, 235. doi: 10.1016/j.cap.2009.05.030

(4) Ram, M. K.; Yavuz, O.; Aldissi, M. Synth. Met. 2005, 151, 77. doi: 10.1016/j.synthmet.2005.03.021

(5) Suri, K.; Annapoorni, S.; Sarkar, A. K.; Tandon, R. P. Sens. Actuators B 2002, 81, 277. doi: 10.1016/S0925-4005(01)009662

(6) Jun, H. K.; Hoh, Y. S.; Lee, B. S.; Lee, S. T.; Lim, J. O.; Lee, D. D.; Huh, J. S. Sens. Actuators B 2003, 96, 576. doi: 10.1016/j. snb.2003.06.002

(7) Malhotra, B. D.; Arora, K.; Chaubey, A.; Singhal, R.; Singh, R. P.; Pandey, M. K.; Samanta, S. B.; Chand, S. Biosens. Bioelectron 2006, 21, 1777. doi: 10.1016/j.bios.2005.09.002

(8) Ameer, Q.; Adeloju, S. B. Sens. Actuators B 2005, 106, 541. doi: 10.1016/j.snb.2004.07.033

(9) Palod, P. A.; Pandey, S. S.; Hayase, S.; Singh, V. Appl. Biochem. Biotechnol. 2014, 174, 1059. doi: 10.1007/s12010-014-0988-x

(10) Patois, T.; Sanchez, J. B.; Berger, F.; Rauch, J. Y.; Fievet, P.; Lakard, B. Sens. Actuators B 2012, 171-172, 431.

(11) Aytaç, S.; Kuralay, F.; Boyacı, İ. H.; Unaleroglu, C. Sens. Actuators B 2011, 160, 405. doi: 10.1016/j.snb.2011.07.069 
(12) Tebizi-Tighilt, F. Z.; Zane, F.; Belhaneche-Bensemra, N.; Belhousse, S.; Sam, S.; Gabouze, N. E. Appl. Surf. Sci. 2013, 269, 180. doi: 10.1016/j.apsusc.2012.10.080

(13) Su, W. C.; Iroh, J. O. Electrochim. Acta 1999, 44, 4655. doi 10.1016/S0013-4686(99)00219-4

(14) Zhang, J.; Kong, L. B.; Li, H.; Luo, Y. C.; Kang, L. J. Mater. Sci. 2010, 45, 1947. doi: 10.1007/s10853-009-4186-0

(15) Omastova, M.; Simon, F. J. Mater. Sci. 2000, 35, 1743. doi: 10.1023/A:1004728502591

(16) Egami, Y.; Yamamoto, T.; Suzuki, K.; Yasuhara, T.; Higuchi, E.; Inoue, H. J. Mater. Sci. 2012, 47, 382. doi: 10.1007/s10853-0115809-9

(17) Rawal, I.; Kaur, A. Sen. Actuators A 2013, 203, 92. doi: 10.1016/ j.sna.2013.08.023

(18) Zhang, L.; Meng, F.; Chen, Y.; Liu, J.; Sun, Y.; Luo, T.; Li, M.; Liu, J. Sens. Actuators B 2009, 142, 204. doi: 10.1016/j. snb.2009.07.042

(19) Wang, J.; Zhang, P.; Qi, J. Q.; Yao, P. J. Sens. Actuators B 2009, 136, 399. doi: 10.1016/j.snb.2008.12.056

(20) Xu, L.; Dong, B.; Wang, Y.; Bai, X.; Liu, Q.; Song, H. W. Sens. Actuators B 2010, 147, 531. doi: 10.1016/j.snb.2010.04.003

(21) Yu, Q. Z.; Wang, M.; Chen, H. Z. Mater. Lett. 2010, 64, 428. doi: 10.1016/j.matlet.2009.11.039

(22) Hsueh, T. J.; Hsu, C. L.; Chang, S. J.; Chen, I. C. Sens. Actuators B. 2007, 126, 473. doi: 10.1016/j.snb.2007.03.034

(23) Su, M. Y.; Wang, J.; Du, H. Y.; Yao, P. J.; Zheng, Y. G.; Li, X. G. Sens. Actuators B. 2012, 161, 1038. doi: 10.1016/j. snb.2011.12.005

(24) Jing, Z. H.; Zhan, J. H. Adv. Mater. 2008, 20, 4547. doi: 10.1002/ adma.v20:23

(25) Huang, J. R.; Wu, Y. J.; Gu, C. P.; Zhai, M. H.; Yu, K.; Yang, M.; Liu, J. H. Sens. Actuators B 2010, 146, 206. doi: 10.1016/j. snb.2010.02.052

(26) Dong, S. Y.; Peng, L.; Liu, D.; Yang, Q. X.; Huang, T. L. Bioelectrochemistry 2014, 98, 87. doi: 10.1016/j. bioelechem.2014.04.001

(27) Su, P. G.; Peng, Y. T. Sens. Actuators B 2014, 193, 637. doi: 10.1016/j.snb.2013.12.027

(28) Yao, T. J.; Li, X.; Quan, L.; Jie, W.; Ren, Z. Y.; Wang, C. X.; Zhang, J. H.; Yu, K.; Yang, B. Polymer 2009, 50, 3938. doi: 10.1016/j.polymer.2009.06.054

(29) Navale, S. T.; Mane, A. T.; Chougule, M. A.; Sakhare, R. D.; Nalage, S. R.; Patil, V. B. Synth. Met. 2014, 189, 94. doi: 10.1016/j.synthmet.2014.01.002

(30) Chougule, M. A.; Dalavi, D. S.; Mali, S.; Patil, P. S.; Moholkar, A. V.; Agawane, G. L.; Kim, J. H.; Sen, S.; Patil, V. B. Measurement 2012, 45, 1989. doi: 10.1016/j. measurement.2012.04.023

(31) Dai, Z. R.; Pan, Z. W.; Wang, Z. L. Adv. Funct. Mater. 2003, 13, 9. doi: 10.1002/adfm.200390013

(32) Grätzel, M. Nature 2001, 414, 338. doi: 10.1038/35104607

(33) Weis, T.; Lipperheide, R.; Wille, U.; Brehme, S. J. Appl. Phys. 2002, 92, 1411. doi: 10.1063/1.1488246

(34) Chen, Y. J.; Zhu, C. L.; Shi, X. L.; Cao, M. S.; Jin, H. B. Nanotechnology 2008, 19, 1 .

(35) Chougulea, M. A.; Sen, S.; Patil, V. B. Synth. Met. 2012, 162, 1598. doi: 10.1016/j.synthmet.2012.07.002 